КАРСАНОВА Елена Созрикоевна - доктор политических наук, доцент департамента политологии и массовых коммуникаций Финансового университета при Правительстве РФ (125993, 2. Москва, ГСП-3, Ленинградский пр-кт, 49); профессор кафедры государственного управления и политических технологий Государственного университета управления (109542, Россия, г. Москва, Рязанский np-кm, 99; e_karsanova@mail.ru)

ГУРШУМОВ Руслан Калевович - аспирант департамента политологии и массовых коммуникаций Финансового университета при Правительстве РФ (125993, Россия, г. Москва, ГСП-3, Ленинградский пр-кт, 49; e_x@те.сот)

\title{
ДИАСПОРА КАК ПОЛИТИЧЕСКИЙ РЕСУРС
}

Аннотация. Диаспоры, наряду с многочисленными акторами международных отношений, такими как транснациональные правительственные/неправительственные организации и финансовые группы, играют все более значимую роль в формировании и реализации внутренней и внешней политики современных государств. В статье обосновывается возможность рассмотрения современных диаспор не только как представителей конкретных этнических/религиозных культур, но и в качестве важного внешнеполитического ресурса и эффективного политического инструмента для продвижения национальных интересов и повышения имиджа страны.

Ключевые слова: диаспора, этническая культура, идентичность, политика, государство

Д

иаспоры, представляя собой мобилизованные группы, объединенные коллективным чувством идентичности и общими интересами, становятся чрезвычайно важным явлением в международной политике. Являясь источником социальных и финансовых инвестиций как минимум для двух наций одновременно, диаспоры непосредственно участвуют в двухсторонних отношениях государств. Кроме осязаемых материальных ценностей, диаспоры способны преумножать эмоционально-культурный, интеллектуальный капитал и устанавливать долговременные каналы связи метрополии с принимающими государствами по всему миру.

Традиционно термин «диаспора» применялся для описания ряда рассеянных по всему миру этнических или религиозных сообществ, покинувших свою родину, но сохранивших при этом устойчивую ориентированность на метрополию, коллективную культурную идентичность и желание культивировать ее на новом месте. В случае исторически «старых» диаспор (евреи, греки или армяне) эта ориентированность нередко выражалась в мифологизированной надежде на возвращение на родину. Подавляющее большинство работ было посвящено еврейской диаспоре.

Американский политолог Роберт Оуэн Кохейн в своей книге «Глобальная диаспора» обращает внимание на 4 этапа, которые преодолели исследования диаспоры: 1960-1970-е гг. (очерки расселения еврейских, армянских, африканских, ирландских сообществ); 1980-е гг. - рассмотрение диаспоры сквозь призму вычленения характеристик групповых социальных категорий народов, живущих вдали от исторической родины (политические беженцы, иммигранты, притесняемые этнические меньшинства и пр.); начало 1990-х гг. - время интенсивных междисциплинарных диаспоральных исследований, в рамках которых была апробирована релевантность термина для рассмотрения проблем национальной идентичности, этнокультурного разнообразия и миграции [Cohen 1997: 129-134]. Настоящее время Р. Кохейн определяет как четвертую, очень перспективную фазу исследований диаспоры, тематическая арка которой охватывает политическую активность и возможность использования потенциала диаспор для развития общественно-политических, экономических и иных связей между государствами. 
Особенно актуально термин «диаспора» стал звучать после известных трагических событий в США 11 сентября, что привело к повышенному вниманию к росту и новым формам диаспор, пониманию необходимости профильной работы с инокультурными этническими сообществами, имеющими транснациональные связи.

В современной зарубежной и отечественной научной литературе регулярно подчеркивается недостаточная проработанность понятийного аппарата для осмысления диаспоры и сведение понятия «диаспора» к статусу беженца, иммигранта либо к вынужденной/сознательной экспатриации и пр.

В отличие от иммигрантских сообществ/национальных меньшинств, диаспоры в большей степени сопротивляются ассимиляции и более ориентированы на поддержание национальной идентичности, культурных ценностей и прочих элементов этнокультурного наследия метрополии. Вероятней всего, именно стремление сохранить эти связи - будь то конфессиональные, лингвистические или аффективные - дифференцирует этот этнокультурный феномен от других общин.

Современные национальные диаспоры не сходны между собой по степени организованности, численности, и общественно-политической активности. К наиболее крупным диаспорам формально относятся китайская (35 млн чел.), индийская (25 млн), русская (25 млн), украинская (12 млн), армянская (около 10 млн чел.); еврейская (8 млн) и другие диаспоры. Кроме того, ряд специалистов указывают на существование курдской (14 млн), ирландской (10 млн), итальянской (8 млн) и других диаспор [Боришполец 2011].

Международный опыт подтверждает, что при планировании политики двухстороннего взаимодействия (государство - диаспора) важно принять во внимание не только количественные и/или структурные характеристики диаспоры, но и их качественные составляющие, т.е. готовность самих диаспор реагировать на государственные инициативы как принимающей страны, так и исторической родины.

Диаспора, представляя собой депозитарий культурного кода, традиций и мифов, не может существовать изолированно, замкнувшись в собственном этнокультурном «контейнере». Находясь длительное время в окружении принимающей культуры, диаспоральные сообщества нередко перенимают часть ее характеристик и даже кооптируют в свой состав представителей доминирующего этнического большинства принимающей стороны. В результате длительного межкультурного взаимодействия этнонациональные нарративы диаспоры, подвергаясь селективной модификации, могут все больше и больше не совпадать с социальными образцами и иными элементами этнокультурных ценностей метрополии. Безусловно, механизмы взаимодействия диаспор с принимающим обществом, их включенность в общественно-политическую жизнь во многом определяются типом политической системы принимающей страны, степенью демократизации, открытости институтов власти и автономии гражданского общества. Проводимая этнонациональная политика, упрощающая этнонациональным диаспорам задачу поддержания этнической, конфессиональной и/или культурной идентичности, как бы противоречиво это ни звучало, создает благоприятные условия для снижения барьеров и «открытости» диаспор [Safran 2007: 159]. В современных условиях динамичного социального взаимодействия исключительно замкнутую эндогенную диаспору встретить сложно: диаспоральная идентичность практически повсеместно представляет собой гибридную идентичность - компромисс между примордиальной и приобретенной на территории проживания идентичностью. 
Как уже отмечалось, степень мобилизации и интеграции диаспоры в инокультурное принимающее общество, ее политическая активность во многом определяется качеством и степенью открытости/закрытости последних. Связи же диаспоры с метрополией - территорией традиционного компактного проживания основной части конкретного этноса - могут модифицироваться в зависимости от той или иной комбинации факторов: если диаспора этнически консолидирована и связь с материнским государством - залог этой консолидации, то понятно, что взаимодействие будет интенсивным. Потребность в активном выражении собственных этнокультурных характеристик может провоцироваться маргинальным статусом членов диаспоры, воображаемым «чувством долга» и иными психологическими факторами, усиливающими ощущение отсутствия исторической родины. Пример доминиканской, сальвадорской и колумбийской диаспор в США демонстрирует непротиворечивость таких выводов: чем длительнее представители диаспор находились в принимающей стране, тем более активно они были вовлечены в политическую жизнь своей этнической родины. Такие диаспоры нередко бросают вызов принимающему обществу и его институтам, становясь значимым барьерным фактором для внутренней и внешней политики.

Если в социальном пространстве формируются комбинированные культуры, то связи с метрополией постепенно ослабевают. Можно предположить, что чем более благоприятны условия для интеграции диаспоры в принимающее общество, тем вероятней ослабление идентификационных связей с родиной и демобилизация диаспоры. Наиболее показателен пример американских евреев, которые стремительно теряют связь с материнским государством на Ближнем Востоке. Проживающие в США евреи в подавляющем большинстве случаев не знают языка, около 70\% вступают в брак с представителями иных культур и лишь 47\% считают свое еврейство «очень важным» [Dan 2019]. Тем не менее нет оснований утверждать, что это однозначно линейный процесс, поскольку даже культурно дистанцированные от родины диаспоры время от времени могут подвергаться значительным колебаниям коллективных воспоминаний. Известно немало случаев, когда в условиях различного рода кризисов диаспоры оперативно реагировали на проблемы метрополий. Так, в период недавнего финансово-экономического кризиса в Греции этническая диаспора в короткие строки мобилизовала средства (100 млн долл.) и поддержала инвестициями и иными мероприятиями свою историческую родину.

Особенно рельефно этнические идентификации и интересы проявляются в периоды эскалации этнополитических противоречий/конфликтов и могут привести к этнической мобилизации диаспоры. Метрополии также могут успешно апеллировать к коллективной памяти, этносимволам и мифам с целью поддержания/возрождения этнической идентичности. Примечателен опыт Израиля, где с 2013 г. функционирует правительственное учреждение - Министерство по делам Иерусалима и диаспоры, ответственное за работу с еврейской диаспорой и позиционирование Израиля на международной арене. Правительство страны, стремясь эффективно использовать политический, экономический и культурный потенциал диаспоры для защиты своих национальных интересов, активно обсуждает идею создания парламента диаспор, а также возможность участия членов зарубежных еврейских общин в процессе принятия политически значимых для государства решений. Руководствуясь формулой: «Отношения должны быть двусторонними», израильская правительственная стратегия предполагает отказ от диаспоральных финансовых инвестиций в экономику страны. Теперь Израиль намерен, отказавшись от капиталовложений диаспоры, оказать финансовую и иную поддержку еврейским общинам в создании за рубе- 
жом «еврейских культурно-просветительских центров, подобных Британскому Совету» [Боришполец 2011].

Активная государственная поддержка диаспор становится действенным и популярным трендом международной деятельности, позволяющим формировать выгодный символический образ и политический имидж страны. Правительства отдельных политий успешно эксплуатируют потенциал диаспор в процессе реализации своих внутри- и/или внешнеполитических стратегий и планов развития. На такие государства, как Венгрия, Греция, Израиль, Индия, Ирландия, Китай, Польша, Франция, можно указать как на успешные с точки зрения работы со «своими» диаспорами. С «чужими» диаспорами, по экспертному мнению, наиболее эффективно взаимодействуют Соединенные Штаты Америки [Боришполец 2011].

Взаимодействие диаспоры с принимающей страной в ограниченном смысле можно рассматривать с точки зрения международных отношений, а использование диаспор в качестве эффективного механизма влияния на принимающее государство для ряда современных стран становится реальной практикой. Несмотря на то что диаспора, в отличие от национальных меньшинств, нормативно не защищена в стране пребывания, в своих коммуникативных связях с принимающим государством она выступает в роли особого коллективного актора, с которым принимающая сторона нередко вынуждена считаться. Хрестоматийным примером является политически активная деятельность Американо-израильского комитета по общественным связям (AIPAC), который структурно тесно связан с еврейской диаспорой. Основное функциональное назначение $A I P A C$ - проведение во внешней политике США произраильского курса. Этой организации многократно удавалось блокировать инициативы Белого дома о выводе израильских войск с части оккупированных ими территорий (План Роджерса 1969 г.), препятствовать планам Г. Киссинджера в пересмотре США своей ближневосточной политики в 1975 г. и Дж. Буша о прекращении строительства поселений на «оккупированных палестинских территориях» [Лозанский 2004: 115-116] и т.д.

Другим интересным примером может выступить деятельность многочисленной и хорошо организованной в ключевых американских штатах армянской диаспоры, которой в 1992 г. удалось пролоббировать принятие конгрессом США поправки к документу1, который блокировал возможность оказания гуманитарной и иной помощи Азербайджану. Более того, после распада Советского Союза армянское лобби в США добилось для метрополии самой объемной гуманитарной помощи среди всех постсоветских республик. Так, в период с 1990-х по начало нулевых годов объем американской гуманитарной помощи Армении составил 239 млн долл., в то время как Азербайджану достался 91,6 млн долл. По сообщению Российско-армянского информационного агентства от 29.09.2019 г., США предоставили Армении дополнительные финансовые ресурсы для проведения политических и социально-экономических реформ. Причем «финансовая помощь выделяется в дополнение к утвержденным $\$ 17,6$ млн. из Фонда экономической поддержки и развития (ЕСФ). \$1,5 млн. предоставляется на борьбу с незаконным оборотом наркотиков, \$600 000 на

1 Freedom Support Act (Акт в поддержку свободы), принят в 1992 г. для экономической поддержки бывших советских республик. Под давлением армянского лобби в документ была внесена 907-я поправка, запрещающая правительству США оказывать помощь Азербайджану ввиду действий последнего по блокаде Нагорного Карабаха и Армении. 
международное военное образование и профподготовку и \$1 млн. на финансирование иностранных вооруженных сил» 1 .

Таким образом, исторический вклад диаспор в международные отношения и их сегодняшний потенциал позволяют определять современную диаспору не только как форму существования сообществ, сложившихся по этнокультурным признакам и проживающих за пределами исторической родины, но и как значимый внешнеполитический/экономический ресурс, инструмент влияния на национальном и международном уровнях. Переосмысление стратегий взаимодействия со своими диаспорами за рубежом на сегодняшний день принципиально практически для всех государств, но в первую очередь для тех, кто стремится к лидирующим позициям в современной мировой политике и успешному продвижению национальных интересов.

\section{Список литературы}

Боришполец К.П. 2011. Мир и диаспоры. Доступ: https://mgimo.ru/about/news/ experts/216064/ (проверено 17.05.2020).

Лозанский Э.Д. 2004. Этносы и лоббизм в США. О перспективах российского лобби в Америке. М.: Международные отношения. 272 с.

Cohen R. 1997. Global Diasporas. L.: University College London Press. 235 p.

Dan D. 2019. Еврейские общины США. 2019/09. Доступ: https://jhist.org/ ajt/2019_10_usa_small.pdf (проверено 17.05.2020).

Safran W. 2007. Democracy, Pluralism, and Diaspora Identity: An Ambiguous Relationship. - Opportunity Structures in Diaspora Relations (ed. by G. Totoricaguena). Reno, Nevada: Center for Basque Studies. P. 157-185.

KARSANOVA Elena Sozrikoevna, Dr.Sci. (Pol.Sci.), Associate Professor of the Department of Political Science and Mass Communications, Financial University under the Government of the Russian Federation (49 Leningradsky Ave, Moscow, Russia, 125993); Professor at the Chair of Public Administration and Political Technologies, State University of Management(99 Ryazansky Ave, Moscow, Russia, 109542; e_karsanova@mail.ru)

GURSHUMOV Ruslan Kalevovich, postgraduate student at the Department of Political Science and Mass Communications, Financial University under the Government of the Russian Federation (49 Leningradsky Ave, Moscow, Russia, 125993; e_x@me.com)

\section{DIASPORA AS THE POLITICAL RESOURCE}

Abstract. Diaspora alongside with the variety of actors in international relations such as transnational government and nongovernment organizations and financial groups plays the growing role in forging and realization of domestic and foreign policy of contemporary states. In the article the authors reason the opportunity to examine contemporary diasporas not only as the representatives of concrete ethnic and confessional cultures, but also as efficient political instruments for promotion of national interests and image making of the country. The governments successfully exploit the potential of the diasporas in the process of implementing their domestic and/or foreign policy strategies and development plans.

Keywords: diaspora, ethnic culture, ethnic identity, policy, state

\footnotetext{
1 Российско-армянское информационное агентство. Доступ: https://rusarminfo.ru/2019/09/27/sshauvelichili-finansovuyu-pomoshh-armenii/ (проверено 17.05.2020).
} 